\title{
Leptospirosis under the bibliometrics radar: evidence for a vicious circle of neglect
}

\section{Cyrille Goarant ${ }^{1}$, Mathieu Picardeau ${ }^{2}$, Serge Morand ${ }^{3,4}$, K Marie McIntyre ${ }^{5,6}$}

\footnotetext{
${ }^{1}$ Institut Pasteur de Nouvelle-Calédonie, Institut Pasteur International Network, Nouméa, New Caledonia

${ }^{2}$ Institut Pasteur, Biology of Spirochetes Unit, French National Reference Centre for Leptospirosis, Paris, France

${ }^{3}$ CNRS ISEM - CIRAD ASTRE, Faculty of Veterinary Technology, Kasetsart University, Bangkok, Thailand

${ }^{4}$ Department of Helminthology, Faculty of Tropical Medicine, Mahidol University, Bangkok, Thailand

${ }^{5}$ Department of Epidemiology and Population Health, Institute of Infection and Global Health, University of Liverpool, Neston, UK

${ }^{6}$ NIHR Health Protection Research Unit in Emerging and Zoonotic Infections, Liverpool, UK
}

Leptospirosis, a paradigm of a One Health disease, mostly imposes its high burden on vulnerable farmers or poor urban active young males in tropical and subtropical regions. Based on the environmental and climatic determinants of leptospirosis, there is strong evidence to suggest that this high burden will increase further in the future, as a consequence of climate change.

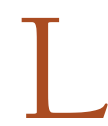

eptospirosis is a bacterial zoonotic disease that affects over 1 million humans, killing 58900 every year [1]. It is mostly a disease of vulnerable populations affecting resource-limited people in urban slums and rural settings in developing countries. Leptospirosis also affects livestock and may cost developing economies hundreds of millions of dollars each year and further impoverish subsistence farmers.

Leptospirosis was identified as the only bacterial zoonosis whose impact will likely increase in response to global change in Europe [2], as expected from its numerous environmental drivers [3]. Indeed, recent reports suggest an actual rise in incidence in several European countries, including Germany, France, Croatia and the Netherlands [4].

However, leptospirosis was not considered in a recent systematic study of climate sensitivity of the most important European human and veterinary pathogens [5]. In this systematic study examining climate-sensitivity [5], a prioritization strategy was developed, which used the H-index scores to rank the 'top' pathogens' (rather than diseases') impact [6]. The H-index prioritisation strategy was validated using correlation between $\mathrm{H}$-indices and global burden estimates for diseases expressed as disability-adjusted life years (DALYs) [7]. Scores for pathogens considered as 'top pathogens' ranged between 524 and 57.

We reanalysed the data, evaluating the reason for non-inclusion of leptospirosis. Although a unique disease entity, leptospirosis is caused by several Leptospira species; the highest H-index score was for Leptospira interrogans $(\mathrm{H}$-index $=45)$, the name for all virulent leptospires until the 1980s. Leptospirosis was therefore not included in the review, because H-indices for the different virulent Leptospira species cannot be treated cumulatively, and no individual species H-index was above the 57 threshold. Re-analysis found that H-indices for "Leptospira" or "Leptospirosis" or "Leptospira OR leptospirosis" were higher than for single species alone, at 87,87 and 105, respectively. These indices would have been inside the priority 
selection window. This omission could be corrected by considering disease entities linked to pathogens within search terms.

The global burden of leptospirosis was recently evaluated by a group of experts (Leptospirosis Epidemiology Research group) convened by World Health Organization (WHO). After extensive data collection and analysis, leptospirosis burden was estimated at 2.90 million DALYs [8]. If included in the correlation (Figure 1, panel A), it falls well below the regression line, providing evidence of insufficient research attention in relation to burden, the hallmark of neglect. Yet, leptospirosis is not included in the WHO list of neglected tropical diseases. Among the consequences identified, leptospirosis research is significantly under-resourced; the research area is unattractive to both funders (Figure 1, panel B, funding data from G-finder, see Table S1 in Online Supplementary Document) and researchers and the leptospirosis research community is shrinking due to lack of visibility and insufficient resources. In practical terms, no significant progress has been made to develop major areas beyond a leptospirosis vaccine [9] and the time-consuming diagnostic reference test for serology [10]; both were developed a century ago.

Leptospirosis, a severe, potentially fatal disease lays at the crossroads of several Sustainable Development Goals. It continues to inflict its high burden on the most vulnerable populations; especially those with least health infrastructure in the developing world, amidst almost total indifference. Breaking the vicious circle of neglect is urgent.

The research community as well as funding agencies tend to show favouritism for "hot topics" instead of allocating resources based on health needs. Leptospirosis is not regarded as an exciting field and leptospirosis research consequently suffers a major lack of resources. Relying on the global burden of diseases to allocate research funding could avoid the vicious circle of neglect in which leptospirosis currently sits.

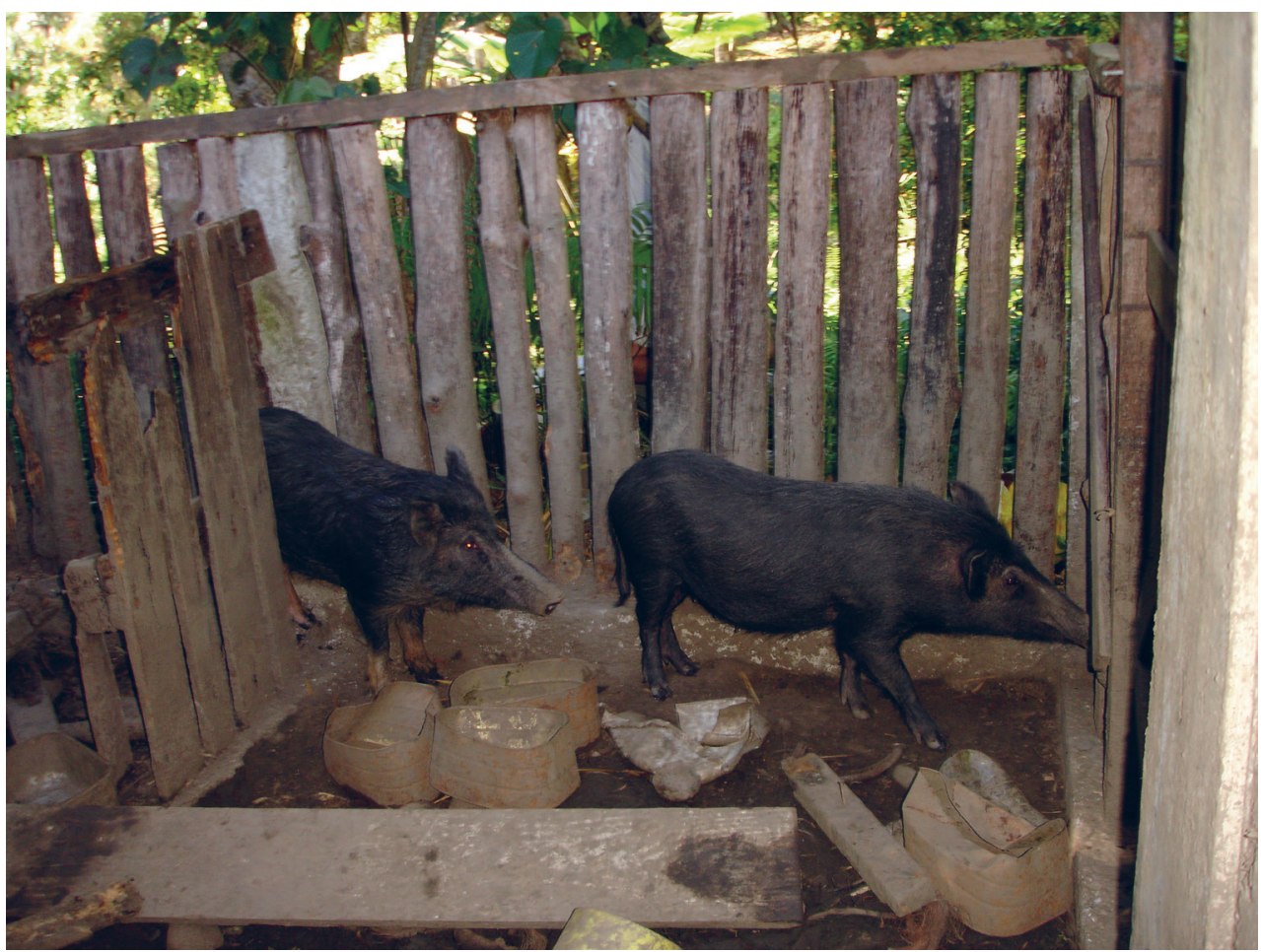

Photo: Backyard subsistence pig farming is probably a major source of leptospirosis in most of the Pacific Island Countries and Territories, where the highest burden is reported from around the globe (from C. Goarant, used with permission) 

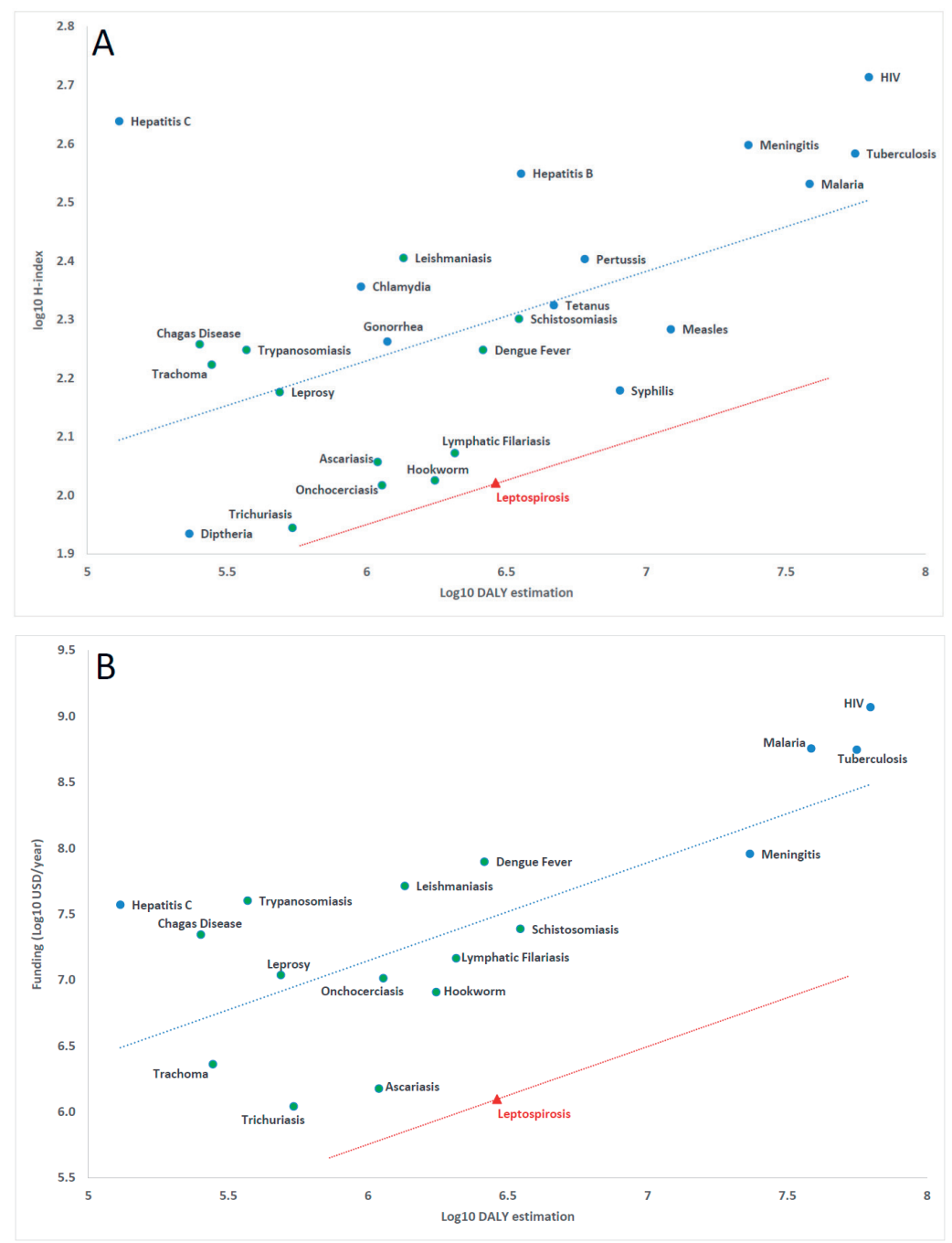

Figure 1. Relationship between the global burden of disease (in DALYs estimated by World Health Organization (WHO) for 2015) and relative research impact (H-index score, calculated using Web of Knowledge and a search period from 1900 to 2018). This provides evidence for the neglect of leptospirosis in panel A. Relationship between the global burden of disease and research funding (annual funding in USD adjusted to 2016 US\$, from G-finder) in panel B, confirming the negative impact on research resources in relation to leptospirosis burden. Green dots are for diseases classified as "neglected tropical diseases" by WHO, a red triangle defines leptospirosis; blue dots are for other diseases. Parallel to the linear regression line calculated using information for all diseases in each plot (blue), the red line illustrates the distance below the regression line for leptospirosis. Detailed data are available in Table S1 in Online Supplementary Document.

Acknowledgements: Thanks are due to Matthew Baylis for his contribution to the initial analysis. CG and MP are members of the Global Leptospirosis Environmental Action Network (GLEAN), which main purpose is to encourage action-oriented research on leptospirosis.

Funding: This study was conducted without specific funding resources

Authorship contributions: CG conceived the study. KMM and CG analysed the data. CG, MP, SM and KMM interpreted the results. All authors significantly contributed to the writing and editing of the MS and agreed with the final content.

Competing interests: The authors have completed the Unified Competing Interest form at www.icmje.org/coi_ disclosure.pdf (available on request from the corresponding author) and declare no conflict of interest.

Additional Material

Online Supplementary Document 
1 Costa F, Hagan JE, Calcagno J, Kane M, Torgerson P, Martinez-Silveira MS, et al. Global morbidity and mortality of leptospirosis: A systematic review. PLoS Negl Trop Dis. 2015;9:e0003898. Medline:26379143 doi:10.1371/journal. pntd.0003898

2 Dufour B, Moutou F, Hattenberger AM, Rodhain F. Global change: impact, management, risk approach and health measures-the case of Europe. Rev Sci Tech. 2008;27:529-50. Medline:18819676 doi:10.20506/rst.27.2.1817

3 Mwachui MA, Crump L, Hartskeerl R, Zinsstag J, Hattendorf J. Environmental and behavioural determinants of leptospirosis transmission: A systematic review. PLoS Negl Trop Dis. 2015;9:e0003843. Medline:26379035 doi:10.1371/journal.pntd.0003843

4 European Centre for Disease Prevention and Control ECDC. Leptospirosis - Annual Epidemiological Report for 2015. Stockholm: ECDC, 2018.

5 McIntyre KM, Setzkorn C, Hepworth PJ, Morand S, Morse AP, Baylis M. Systematic assessment of the climate sensitivity of important human and domestic animals pathogens in Europe. Sci Rep. 2017;7:7134. Medline:28769039 doi:10.1038/ s41598-017-06948-9

6 McIntyre KM, Setzkorn C, Hepworth PJ, Morand S, Morse AP, Baylis M. A Quantitative Prioritisation of Human and Domestic Animal Pathogens in Europe. PLoS One. 2014;9:e103529. Medline:25136810 doi:10.1371/journal.pone.0103529

7 McIntyre KM, Hawkes I, Waret-Szkuta A, Morand S, Baylis M. The H-index as a quantitative indicator of the relative impact of human diseases. PLoS One. 2011;6:e19558. Medline:21625581 doi:10.1371/journal.pone.0019558

8 Torgerson PR, Hagan JE, Costa F, Calcagno J, Kane M, Martinez-Silveira MS, et al. Global rurden of Leptospirosis: Estimated in terms of Disability Adjusted Life Years. PLoS Negl Trop Dis. 2015;9:e0004122. Medline:26431366 doi:10.1371/ journal.pntd.0004122

9 Ido Y, Hoki R, Ito H, Wani H. The prophylaxis of Weil's disease (Spirochaetosis Icterohaemorrhagica). J Exp Med. 1916;24:471-83. Medline:19868055 doi:10.1084/jem.24.5.471

10 Martin L, Pettit A. Sero-diagnostic de la spirochaetose icterohaemorrhagique. Bull Mem Soc Med Hop Paris. 1918;42:672-5.

\section{Correspondence to:}

Cyrille Goarant

Institut Pasteur de Nouvelle-Calédonie

11 avenue Paul Doumer

98800 Nouméa

New Caledonia

cgoarant@pasteur.nc 